\title{
ESTANISLAU KRUSZYNSKI
}

\author{
JOSE ALEXANDRE M. PIGATTO
}

Doutor pelo PROLAM/ USP - Mestre e Bacharel em Ciências Contábeis pela FEA/ USP

\author{
Professor do CESNORS/ UFSM \\ pigatto71@gmail.com
}

Em 1978, o contabilista José Mancini, em uma iniciativa modesta, na cidade de São Carlos, no Estado de São Paulo, conseguiu publicar um livro para preservar a memória de seu antigo mestre e sócio, o senhor Estanislau Kruszynski (Stanislaw Kruszyński) e, também, para comemorar o Dia do Contabilista. O livro, ao que parece, estava escrito desde 1972. Ao escrevê-lo, Mancini aponta para a existência de um elo na história da Contabilidade Pública, ligando o Império com a República Velha no Brasil, que, todavia, ainda precisa ser comprovado. Tal evento explicaria o início de um salto qualitativo da Contabilidade Governamental entre 1892 e 1922, quando a formação contábil, no Brasil, ainda era efêmera.

O livro possui 86 páginas, distribuídas ao longo de quatro capítulos com mais um capítulo final de esclarecimentos. O primeiro capítulo é o mais importante para a história contábil brasileira e relata como Kruszynski chegou ao Brasil, atribuindo-Ihe o pioneirismo da grande reforma na Contabilidade Pública, segundo a partida dobrada e um esquema Logismográfico.

O segundo capitulo é denominado "Reminiscências" e descreve a vida pessoal e profissional de Kruszynski em São Carlos e os determinantes da sua vinda para aquela cidade. No terceiro capítulo, Mancini escreve sobre a história da Contabilidade e dá grande ênfase à divergência entre o pensamento de Cerboni e Bèsta no final do século XIX. O autor atribui o conteúdo desse capítulo aos ensinamentos que o próprio Kruszynski lhe teria transmitido. O quarto capítulo é uma retransmissão de algumas anedotas contábeis que Kruzsynski utilizava para satirizar o personalismo e a falta de objetividade científica sobre as causas dos registros contábeis.

Para entender a reforma e a importância de Kruszynski, é necessário compreender qual era a contabilidade praticada até então. Com a vinda da Corte Real, em 1808, diversas instituições no setor público brasileiro foram criadas e outras tantas, reforçadas. Tão logo 
chegou, Dom João VI criou o Real Erário, o Conselho da Real Fazenda e três Contadorias Gerais (OLIVEIRA, 1958, p. 16; VEIGA, 1975, p. 5). De acordo com Oliveira (1958, p. 16), o alvará de criação do Erário Régio e do Conselho da Fazenda foi a pedra fundamental do nosso sistema financeiro governamental, a partir do qual, "[...] baseado na administração portuguesa, partiram todas as nossas organizações posteriores que nela se inspiraram". 0 referido alvará continha seis capítulos versantes sobre os serviços do Erário, destacandose o capítulo II, que tratava das entradas das rendas no Erário, e o capítulo III relativo às saídas ou às despesas do Erário (OLIVEIRA, 1958, p. 16). Os conceitos de receita e despesa, nessa época, seguiam a lógica de ingresso e desembolso, ou seja, o regime de caixa e a única espécie de riqueza (ativo) passível de registro era o disponível.

Com a proclamação da Independência, a Constituição, promulgada em 25 de março de 1824, já continha dispositivos orçamentários, embora a primeira lei orçamentária só viesse a ser aprovada em 1827 (VEIGA, 1975, p. 5; MARTINS, 1988 p. 214). Lecionam Oliveira (1958, p. 17) e Barros (1991, p. 285) que o artigo 170 da Constituição de 1824 ordenava o seguinte:

A receita e a despesa da Fazenda Nacional serão encarregadas a um Tribunal, debaixo do nome de Tesouro Nacional, aonde em diversas estações devidamente estabelecidas por lei se regulará sua administração, arrecadação e contabilidade em recíproca correspondência com as tesourarias e autoridades do Império.

Faz-se, ademais, interessante observar o mandamento constitucional do artigo 172, apanhado por Barros (1991, p. 285), sobre a prestação de contas:

O Ministro de Estado da Fazenda, havendo recebido dos outros Ministros os orçamentos relativos às despesas das suas repartições, apresentará na Câmara dos Deputados anualmente, logo que estiver reunida, um balanço geral da receita e despesa do Tesouro Nacional do ano antecedente e, igualmente o orçamento geral de todas as despesas públicas do ano futuro, e da importância de todas as contribuições, e rendas públicas.

Contudo, o alcance da Contabilidade não se estendia para o patrimônio. A confrontação dos ingressos com os gastos chamava-se "balanço"; constituindo, praticamente, um fluxo de caixa, haja vista os conceitos de receita e despesa já elucidados.

Em 1830, surgiu o primeiro orçamento geral voltado para o exercício financeiro de 1831 (VEIGA, 1975, p. 5). Em 26 de abril de 1832, um regulamento do Tribunal do Tesouro Público Nacional instruía as Tesourarias do Império nas suas atividades de escrituração e 
contas. A escrituração dava-se no livro "Caixa Geral” (OLIVEIRA, 1958, p. 18). O controle, portanto, continuava nas Tesourarias.

A importância atribuída a Kruszynski como idealizador da reforma da Contabilidade Pública surgiria no final do século XIX. Oliveira (1958, p. 20) confirma o caso relatado no livro de Mancini, ou seja, que Rivadávia Correia, no início do século XX, ao assumir a pasta da Fazenda, verificou que o controle do Tesouro Nacional não passava de livros caixas, o que confirma a tese da prevalência do regime de caixa nas finanças públicas da época. Passaram-se quase 100 anos desde a chegada da Família Real sem grandes mudanças na Contabilidade Pública Brasileira. Kruszynski, em tese, teria contribuído de modo decisivo, para a modernização da Contabilidade Pública.

Em outubro de 1892, a municipalidade de São Carlos começou a utilizar a partida dobrada, segundo um esquema Logismográfico, elaborado pelo imigrante polonês "Estanislau" Kruszynski a pedido de Carlos de Carvalho, que ocupou, entre outros cargos, o de coletor de rendas e de guarda-livros da Câmara Municipal. Até então, a escrituração não passava do registro de ingressos e desembolsos (MANCINI, 1978, p. 5-7). Também, nesse processo histórico retomado pelo livro, é interessante notar que a primeira escola de comércio brasileira foi a Escola de Comércio Álvares Penteado, fundada em 1902, na cidade de São Paulo. A questão fundamental para determinar o pioneirismo de São Carlos na reforma contábil e colocar Kruszynski no seu devido lugar na história brasileira é encontrar a prova material dessa nova Contabilidade, ou seja, os seus registros. O saudoso professor Nelson Petri, acompanhado do autor dessa resenha, foi a São Carlos, em 2005, em busca de provas e não pode encontrá-las. Acrescente-se que também o Sr. Carlos Honório Martins de Oliveira, contabilista em São Carlos, divulgador da obra de Mancini e da biografia de Kruszynski, envidou esforços na busca desses primeiros registros contábeis da municipalidade que comprovariam o relato de Mancini, mas até o momento nada foi encontrado.

O conhecimento contábil de Kruszynski advinha do fato de ele ter cursado engenharia em Zurique, na Suíça. A Contabilidade fazia parte do currículo de engenharia e Kruszynski pode testemunhar o embate teórico entre o personalismo de Cerboni e o positivismo de Bèsta (MANCINI, 1978 p. 35). Ressalve-se que o conteúdo de Contabilidade também era ensinado nos cursos de Engenharia no Brasil (MARTINS, DA SILVA, RICARDINO, 2006 p. 117).

Por ter lutado contra a invasão russa em seu país, a Polônia, Kruszynski foi obrigado a emigrar para o Brasil (MANCINI, 1978 p. 14). A partir de Carlos de Carvalho, Kruzynsksi teria encontrado uma oportunidade para transferir a tecnologia da Contabilidade Pública italiana para o Brasil. Essa interação intelectual entre Carvalho e Kruszynksi teria induzido uma primeira reforma na Contabilidade Pública do Brasil.

O indício de que a experiência, não comprovada, de São Carlos seria o estímulo para a reforma contábil do setor público, aparece indiretamente nas memórias de Francisco 
D’Áuria no livro Cinqüenta Anos de Contabilidade, de 1953. Da mesma forma que Mancini, D'Áuria explicou que a crise do café, no início do século passado, chamou a atenção do Tesouro Paulista para a necessidade de uma intervenção estatal nesse importante setor da sua economia. Diante desse desafio e face à tecnologia de finanças públicas à época, a saída natural era o aprimoramento da Contabilidade do Estado. Carlos de Carvalho, já reconhecido como um excepcional guarda livros, que revolucionara a Contabilidade municipal em São Carlos, foi então recrutado pelo Tesouro estadual para essa tarefa (D'ÁURIA 1953, p. 15-16). A primeira reforma da Contabilidade Pública Brasileira iniciou de baixo para cima, ou seja, do Município de São Carlos para o Estado de São Paulo.

Em 24 de agosto de 1906, Francisco D'Áuria ingressou na seção de Contabilidade da Secretaria da Fazenda do Estado de São Paulo, que era liderada por Carlos de Carvalho, para trabalhar justamente no exame e na escrituração das operações de valorização do café.

[...] trabalhando com Carlos de Carvalho, desde 24 de agosto de 1906, e falando com ele, diariamente, em obras e assuntos de contabilidade, comecei a colecionar nomes de autores. Giovanni Massa, Fábio Bésta, Eugênio Léautey, Gitti, Cerboni, - passaram a ser familiares para mim, e Carlos deveria ser o meu "catalogo vivo" para o futuro enriquecimento da minha minúscula biblioteca (D’ÁURIA 1953, p. 14).

Esse conhecimento de Carlos de Carvalho, que não frequentou uma escola formal de Contabilidade, realmente chama a atenção e também é um indício da influência de Kruszynksi, pois este último é quem recebera a educação contábil na Europa e, que teve no período considerado, contato com o primeiro.

No Governo Central, em 1914, o ministro Rivadávia Correa, ao tentar levantar um empréstimo com banqueiros ingleses, encontrou a exigência daqueles da apresentação de um balanço. Ao buscar o tal balanço, conseguiu somente dispor de uma demonstração com oito anos de atraso (D'ÁURIA, 1953 p. 40). Assim, no ano de 1914, iniciou-se a terceira etapa da primeira reforma da Contabilidade Pública, ou seja, a tecnologia da Contabilidade de São Paulo foi transferida para a União, quando os servidores Francisco D'Áuria e Carlos Levi Magano foram comissionados para o governo central. Essa situação durou até o final do ano de 1916 (OLIVEIRA, 1958 p. 21). Com a nomeação de Rivadávia como intendente da prefeitura do Distrito Federal - na ocasião, o Rio de Janeiro -, aqueles técnicos foram convidados para, paralelamente, remodelar a Contabilidade daquele ente distrital (D'ÁURIA, 1953 p. 45). Concretizava-se assim, o primeiro ciclo de reformas na Contabilidade brasileira que culminaria, em 1922, com a promulgação do Código de Contabilidade e o seu Regulamento. 


\section{REFERÊNCIAS}

D’ÁURIA, Francisco. Cinqüenta Anos de Contabilidade (1903 - 1953). São Paulo: Indústria Gráfica Siqueira, 1953.

MANCINI, José. Estanislau Kruszynksi - em comemoração ao dia do contabilista. São Carlos: Associação dos Contabilistas, 1978.

MARTINS, Eliseu; DA SILVA, Amado Francisco; RICARDINO, Álvaro. Escola Politécnica: Possivelmente o primeiro curso formal de Contabilidade Formal de Contabilidade do Estado de São Paulo. Revista Contabilidade e Finanças. São Paulo, n. 42, p. 113-122, set/dez, 2006.

OLIVEIRA, Manoel Marques. Lições de Contabilidade Pública. Teoria e Prática. São Paulo: Atlas, 1958.

VEIGA, Clóvis de Andrade. Direito Financeiro Aplicado. São Paulo: Editora Revista dos Tribunais, 1975. 